\title{
Nissan gasoline engine strategy for higher thermal efficiency
}

Rising highly concern about the environment has led to demands for the improvement of the efficiency of gasoline engines. Engine thermal efficiency will reach about $40 \%$ by technologies as boosted EGR, miller cycle and so on. This evolution trend will be continuously required to survive engines for the future. In this background, further improvement based on theoretical thermal efficiency of high compression ratio and specific heat capacity should be promoted. In addition, energy loss reduction such as represented by cooling loss and friction is also very important for the efficient and effective improvement. NISSAN's challenges will be introduced to solve these propositions.

Key words: gasoline engine, downsizing turbo, variable compression ratio

\section{Introduction}

In order to realize a sustainable society, the mobility solution promoted by Nissan is based on two pillars. The first one is the widespread use of "Zero Emission" vehicles that produce no tailpipe $\mathrm{CO}_{2}$ emissions, and the second one is the thorough improvement of efficiency of vehicles equipped with internal combustion engines.

Regarding the widespread use of "Zero Emission" vehicles, Nissan aims for $25 \%$ sales ratio by 2025 . However, simple manufacture and sale of the zero-emission vehicles is only a first step towards the widespread use of "Zero Emission" vehicles. The key factors to spread "Zero Emission" vehicles are the innovation in technology and the comprehensive effort in the construction of social infrastructure, including development and installation of quickcharging stations. Nissan focuses on promoting zeroemission mobility through these activities.

On the other hand, regarding the improvement of vehicles equipped with internal combustion engines, thermal efficiency of almost $40 \%$ will be achieved by generation change before 2020, but this is just a passing point. Due to the progress in lean-burn technologies such as turbocharging EGR, turbocharging Lean, the roadmap to the $45 \%$ thermal efficiency of internal combustion engines has already been seen. In order to have the internal combustion engines as valuable power source in the future, continuous effort to improve thermal efficiency is expected. The key for further continuous improvement of thermal efficiency is supposed to be the reduction of cooling loss and implementation of high compression ratio. However high compression ratio needs a long stroke that requires a geometrically unreasonable shape for an automobile internal combustion engine.

This is a major physical obstacle on the path to the high compression ratio engine. The link mechanism adopted by the new VC-T (Variable Compression-Turbo) engine developed by Nissan, in addition to enabling variable compression ratio functionality has the effect of changing the motion of the piston link. Because of this effect, the physical obstacle on the path to high compression ratio can be overcome and long stroke can be implemented geometrically and reasonably. In a sense, it can be said that by acquiring this link mechanism technology, internal combustion engines gain the evolution potential for another 100 years.

Although it seems a big challenge to aim for further significant improvement after thermal efficiency of internal combustion engines exceeds $45 \%$, there are already cases of such high thermal efficiency being achieved in marine engines, power plants, etc. One of the key points is how the internal combustion engines is used. By narrowing down operating conditions, such as constant load operation, limiting rotation speed etc. further improvement can be expected.

In autumn 2016, Nissan launched a new electric powertrain "e-POWER", a new power unit combining a gasoline engine and a Battery Electric Vehicle (BEV) motor. The "ePOWER" has the potential to achieve a higher level of economic efficiency, because engine and tires are not directly connected mechanically; even when the internal combustion engine is used as engine for power generation it can operate with most effective rotation speed and load.

\section{Nissan sustainability strategies}

In order to realize sustainable society, Nissan adopted a long-term vision of reducing $\mathrm{CO}_{2}$ emissions of new cars by $90 \%$ by 2050 comparing to 2000 (Fig. 1).

The widespread use of Battery Electric Vehicles (BEVs) that do not emit $\mathrm{CO}_{2}$ and other exhaust gases when running is a major pillar supporting this long-term vision. Such vehicles have already entered mass-production and even more effort is going into development. By using technologies for improving the energy density of lithium batteries, reduction of running resistance etc. Nissan has already succeeded in development of technology that enables driving range per one charge comparable to that of ordinary gasoline vehicles [1]. However, at the present time, replacing all vehicles with BEVs looks problematic from both cost and technical points.

For example, the energy density of current lithium batteries is about $100 \mathrm{Wh} / \mathrm{kg}$, and while there are technologies allowing in excess of $200 \mathrm{Wh} / \mathrm{kg}$ density in the future, in order to travel long distances heavier batteries must be carried continuously. Considering that the energy density of gasoline is about $12,000 \mathrm{Wh} / \mathrm{kg}$, in order to make the selection of a BEV as a vehicle for long distance travel rational, further improvement of battery energy density is required in the future. In other words, even if BEVs become affordable and widespread, vehicles running on liquid fuel will continue to play an important role. There is no doubt, that to reduce the total amount of $\mathrm{CO}_{2}$ emission globally, the improvement of fuel efficiency of vehicles equipped with internal combustion engines is extremely important. 


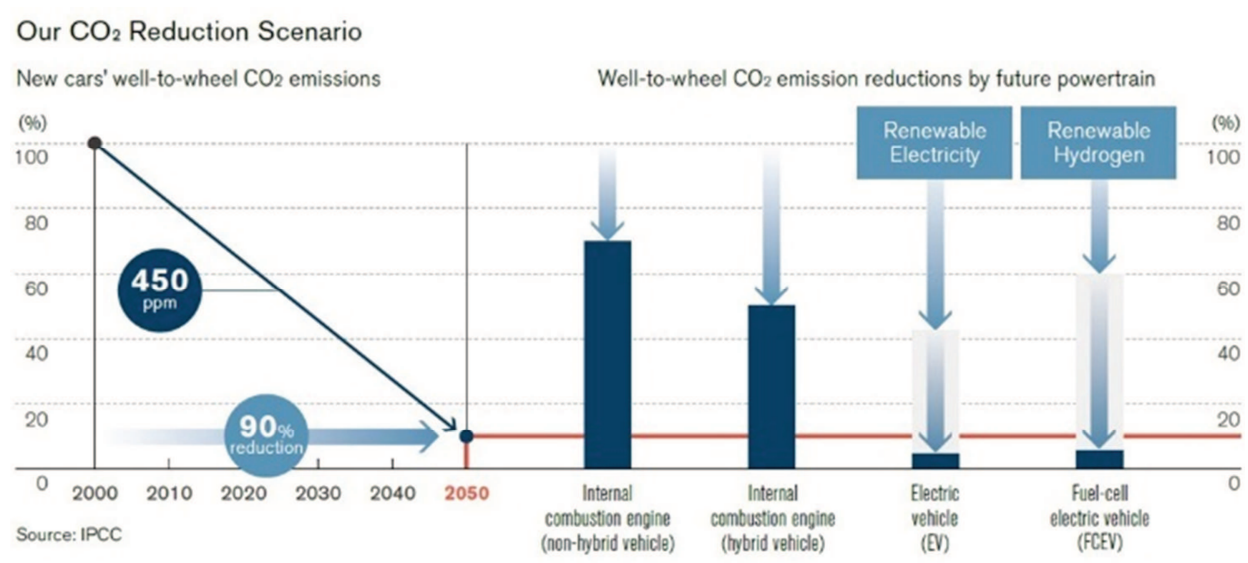

Fig. 1. Scenario for $\mathrm{CO}_{2}$ emission volume reduction

Based on the above, the sustainable mobility solution promoted by Nissan is based on two pillars. The first one is the "Zero Emission" vehicles which produce no tailpipe $\mathrm{CO}_{2}$, and the second one is "PURE DRIVE", the thorough improvement of efficiency of vehicles equipped with internal combustion engines (Fig. 2).

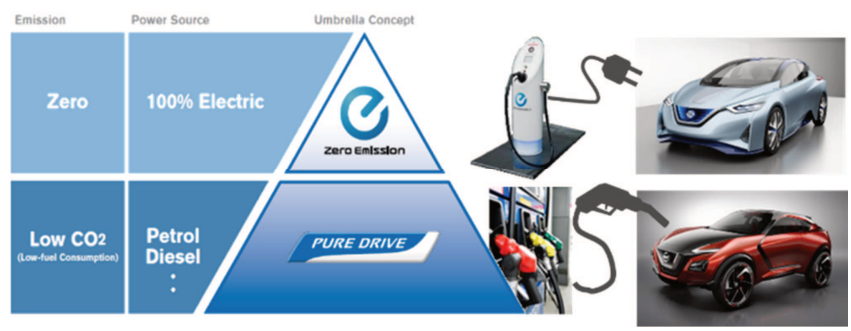

Fig. 2. The sustainable mobility solution based on two pillars

\section{Evolution of PURE DRIVE}

Nissan is focusing not only on Zero Emission vehicles, but also on improving efficiency of vehicles equipped with internal combustion engines using such technologies as downsizing turbocharging technology, CVT etc. The most important task required to further improve the efficiency of vehicles with internal combustion engines is the improvement of thermal efficiency of the internal combustion engine itself. The thermal efficiency of internal combustion engines used in passenger cars has continuously evolved from the past to the present without stopping (Fig. 3). In order to have the internal combustion engines as valuable power source in the future, continuous effort to improve thermal efficiency is expected.

Thermal efficiency of almost $40 \%$ will be achieved by generation change before 2020, but this is just a passing point. Due to the progress in lean-burn technologies, such as turbocharging EGR, turbocharging Lean, the roadmap to $45 \%$ thermal efficiency of the internal combustion engines has already been seen (Fig. 4). Even higher levels of thermal efficiency can be achieved by reducing cooling loss and further improving the compression (expansion) ratio. With the current level of cooling loss, significant improvement of thermal efficiency by improving compression ratio can not be expected, but there is still a place for thermal efficiency improvement by increasing the compression ratio while greatly reducing the cooling loss (Fig. 5).

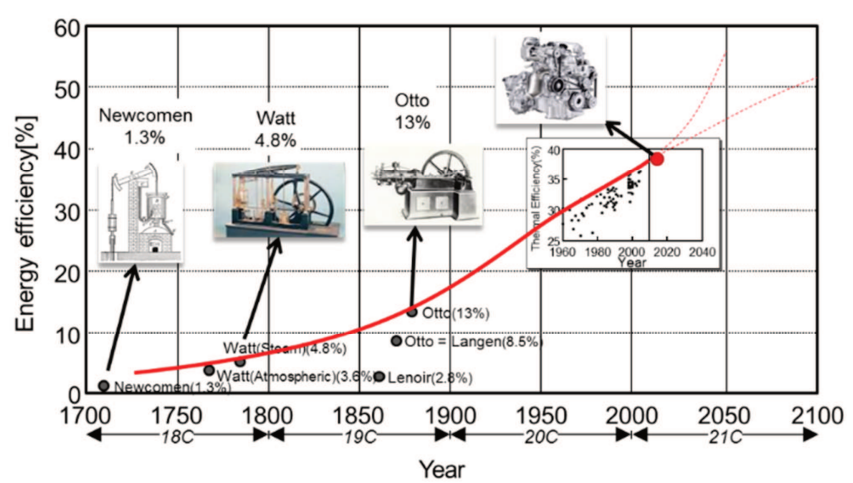

Fig. 3. Evolution of thermal efficiency of internal combustion engines

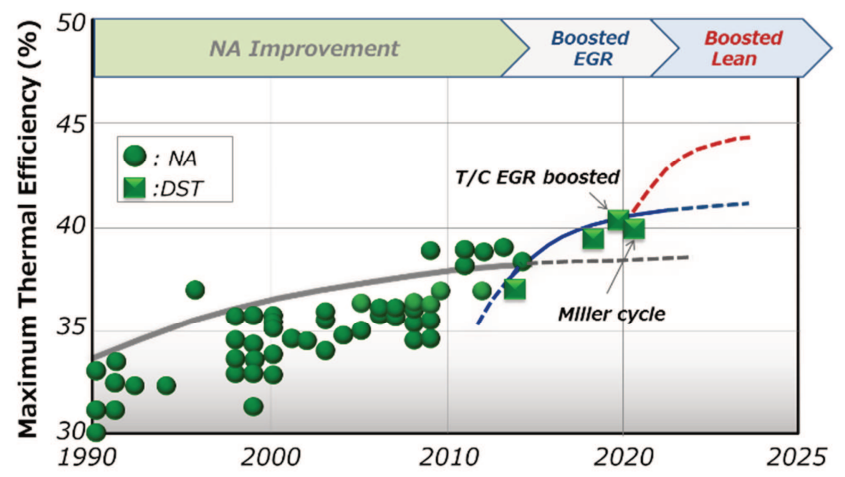

Fig. 4. What is the next key driver to evolve?

Research and development of high response heat insulating films and heat insulating materials has been advanced as a measure to further improve the cooling loss from the current level; these results are expected to achieve a breakthrough in reduction of the cooling loss in internal combustion engines [2]. On the other hand, when looking at history, the compression ratio has expanded together with the evolution of internal combustion engine, and it looks like the demand for improvement of compression ratio will continue as long as engine continues to evolve. In order to realize stable combustion at high compression ratio, a long stroke is required at the same time (Fig. 6). 


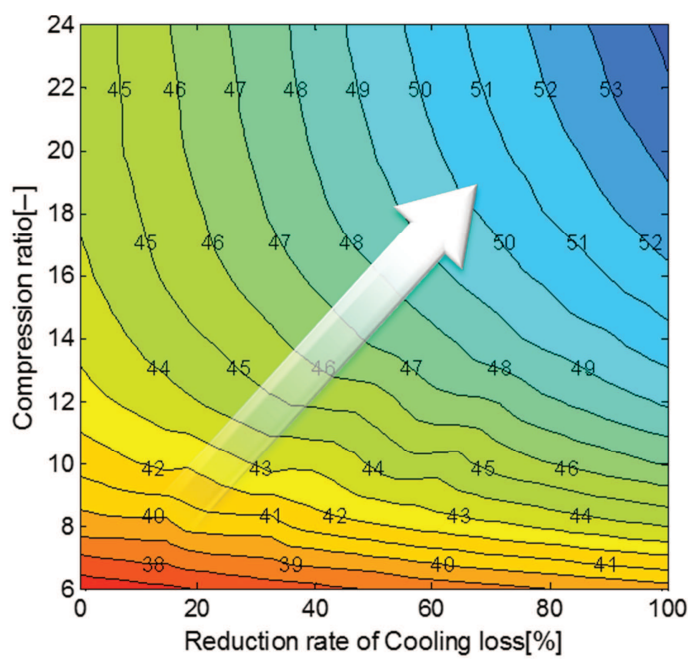

Fig. 5. Potential to improve thermal efficiency

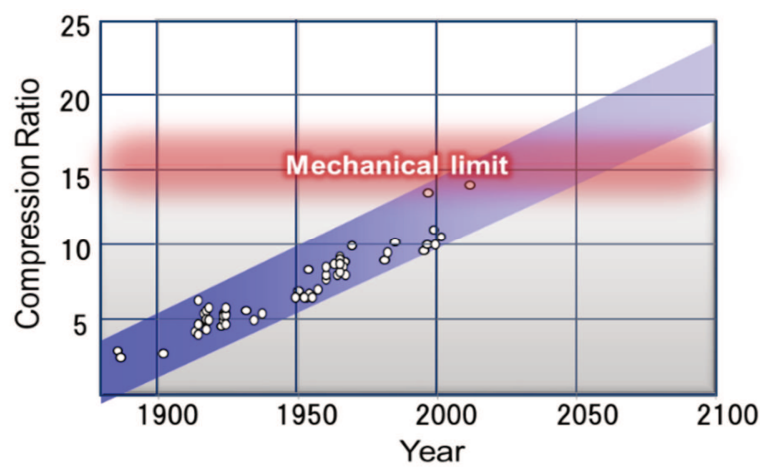

Fig. 6. Evolution of compression ratio of gasoline internal combustion engines

However, the long stroke necessary to achieve a compression above a certain level requires an extremely large engine height to realize it geometrically, which makes it an unsuitable shape for an automobile internal combustion engine. This is a major physical road block on the path to the high compression ratio engine.

At the 2016 Paris Motor Show Nissan presented the world's first innovative engine technology "VC-Turbo" from the Infinity brand (Fig. 7). The "VC-Turbo" engine adopts the world's first variable compression ratio technology using link mechanism (Fig. 8). This technology makes the 4 cylinder "VC-Turbo" engine an unprecedentedly advanced engine realizing the regular performance of a 6 cylinder gasoline engine with top-level thermal efficiency at the same time (Fig. 9).

The link mechanism adopted by the VC-Turbo engine, has in addition to enabling variable compression ratio functionality the effect of changing the motion of piston link [3, 4]. Because of this effect the physical obstacle on the path to high compression ratio can be overcome and long stroke implemented geometrically and reasonable (Fig. 10). In a sense, it can be said that by adopting this link mechanism technology, internal combustion engines gained the evolution potential for another 100 years.

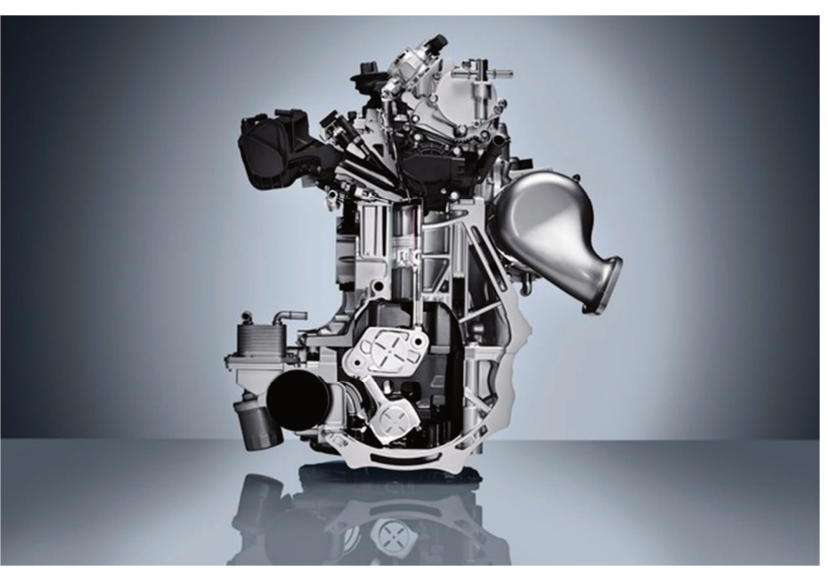

Fig. 7. INFINITI VC-Turbo

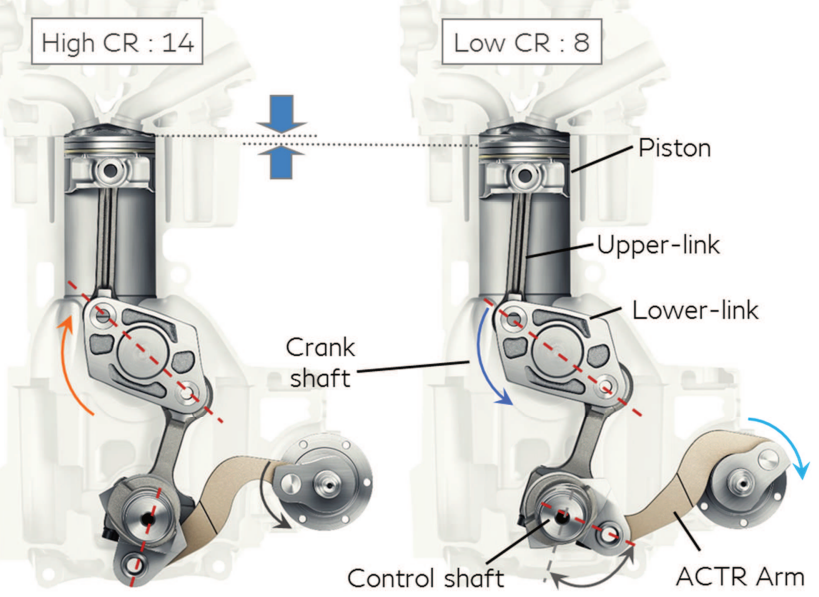

Fig. 8. Overview of the VC-Turbo engine
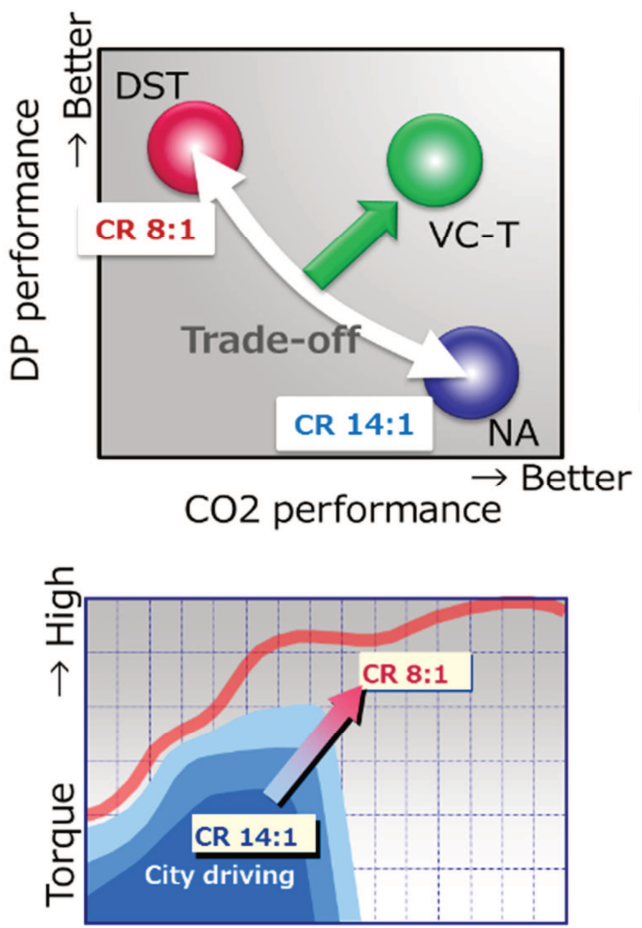

Engine Rev. $\rightarrow$ High

Fig. 9. Performances overview of the VC-Turbo technology 


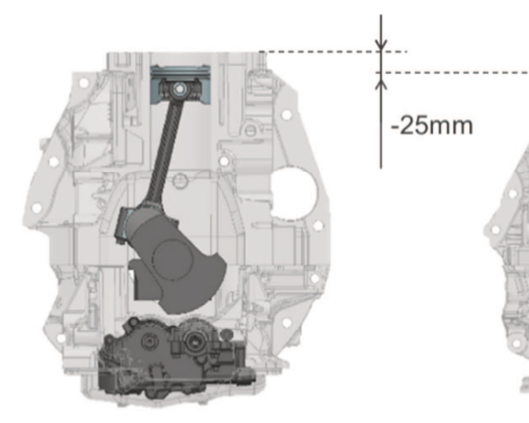

Conventional engine

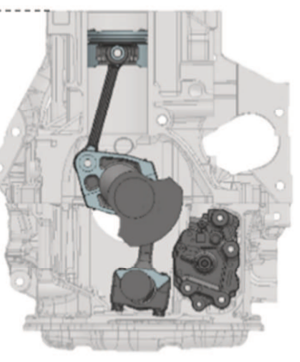

VC-Turbo

Fig. 10. Impact for engine height

\section{Considerations for further evolution of PURE DRIVE combined with BEV technology}

Although it seems a big challenge to aim for further significant improvement after thermal efficiency of internal combustion engines exceeds $45 \%$, there are already cases of such high thermal efficiency in marine engines, power plants etc. One of the key points is how the internal combustion engines is used. By narrowing down operating conditions, such as constant load operation, limiting rotation speed etc. further improvement can be expected. As an internal combustion engine for electrified powertrain for automobiles, revision of specifications more specialized for power generation can be considered a major breakthrough (Fig. 11). However, in this case the use of the internal combustion engine in automobile also has to be changed.

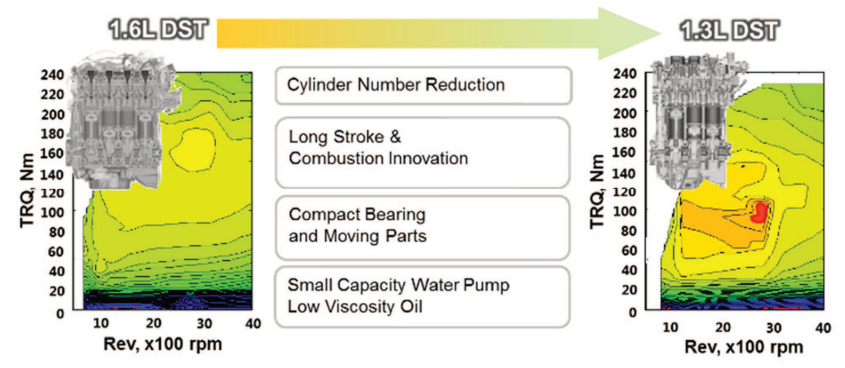

Fig. 11. Example of specialization for power generation

In autumn 2016, Nissan launched a compact car "NOTE e-Power" equipped with a new electric powertrain "ePOWER"; combining a gasoline engine and a BEV motor (Fig. 12). Although the power source of the "e-POWER" is an internal combustion engine, it is completely different from hybrid systems widely used in general compact cars because it is a new electric powertrain which has $100 \%$ motor driven EV operation (Fig. 13).

The "e-POWER" has the potential to acquire a higher level of economic efficiency, because the engine and tires are not directly connected mechanically, even when the internal combustion engine is used for power generation, it can operate with most effective rotation speed and load.

The following measures can be considered as examples of revisions to the internal combustion engine specification specially for power generation: reducing friction by lowering the maximum rotation speed, further downsizing by sacrificing responsiveness in the low rotation speed range, cylinder cutout incorporating measures against NVH, limit-

ing operating rotation speed range, and so on. Radical improvement of compression (expansion) ratio is also important here, and realization of high compression (expansion) ratio by making super long stroke using link mechanism contributes to further efficiency improvement. While in this case there is a possibility that performance at high rotation speed may be sacrificed, this does not constitute a problem for the power generation function.

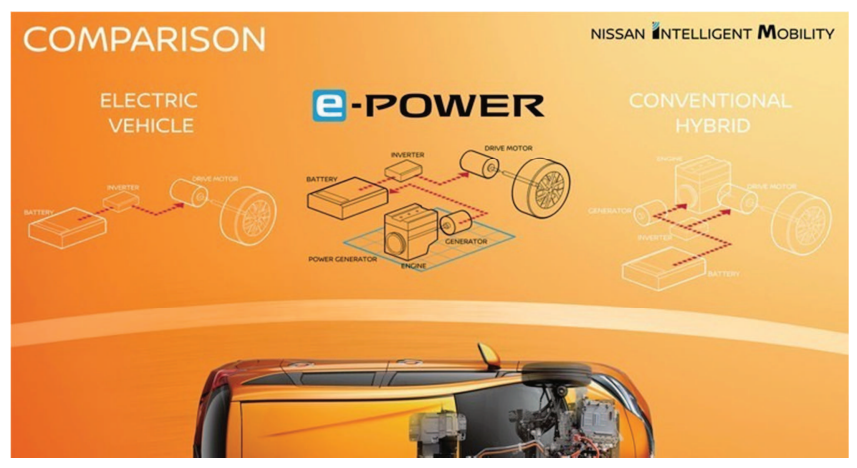

Fig. 12. Concept of "e-POWER"

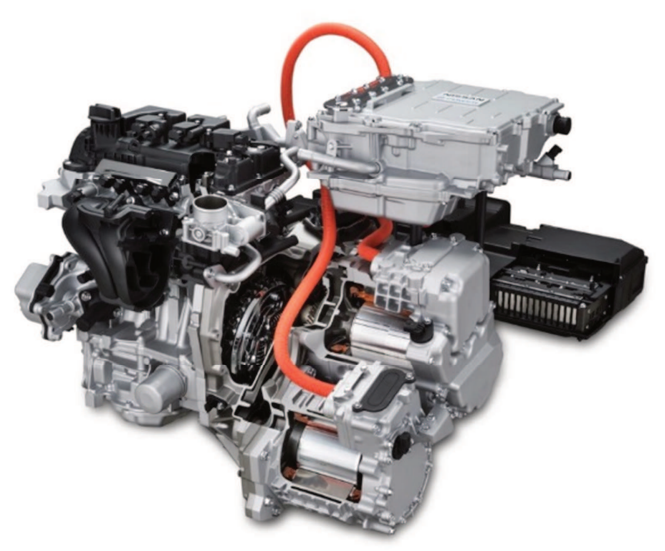

Fig. 13. Fully integrated e-POWER powertrain

Considering the above changes, the thermal efficiency of the internal combustion engine can be further improved by about $5 \%$; as a result, the thermal efficiency of the internal combustion engine will reach $50 \%$.

\section{Trend of downsizing}

The ICE will be able to operate at most effective point (rev. torque) only if it specialized as a "generator" like epower. Running time will be reduced because the ICE will always operate at its most effective point on demand dependent on driving situation. A key requirement will be to ensure that the internal temperature quickly increases at engine start timing in order to operate at most effective point. The energy for raising temperature will became an issue in the future as with improving BSFC the energy available will lessen [5].

Nissan assumes that making lower thermal energy capacity by reducing displacement will be effective via downsizing and will be focused on. As mentioned before, VC-T offers appropriate compression ratio depending on the operating situations by using unique link system. VC-T will be able to realize further downsizing, compared to conven- 
tional ICE's due to avoiding knock in high power and high torque area by using low compression ratio (Fig. 14). Thus downsizing will be promoted more by using variable compression ratio or similar mechanism in order to minimize the warming up energy needed.

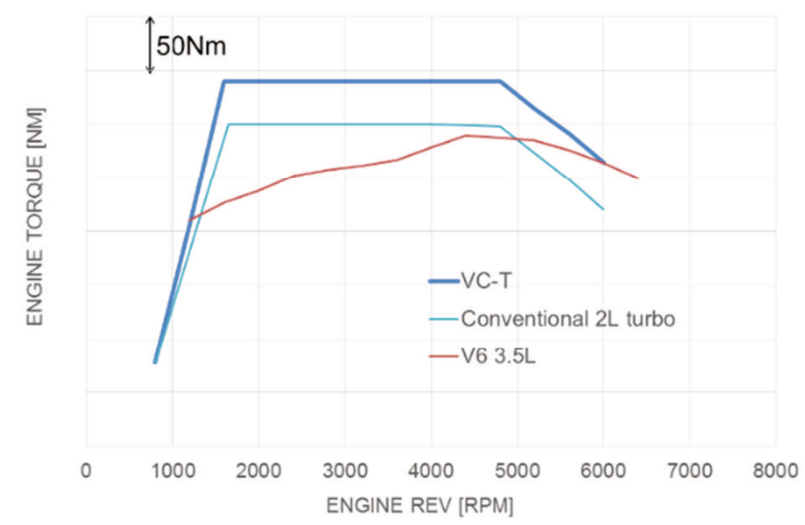

Fig. 14. Downsizing by VC-T

\section{Summary}

1) The mobility solution promoted by Nissan is based on the two pillars. The first one is the "Zero Emission" vehicles which produce no $\mathrm{CO}_{2}$, and the second one is "PURE DRIVE", the thorough improvement of efficiency of vehicles equipped with internal combustion engines.

2) For "PURE DRIVE", Nissan will put our strength in technological development to continuously improve the thermal efficiency of the internal combustion engine and contribute to global reduction of $\mathrm{CO}_{2}$ emission. The variable compression ratio technology for internal combustion engine using the link mechanism is one of the important key technologies for this purpose.

3) The e-POWER combined with the "Zero Emission" technology in vehicles equipped with internal combustion engines shows a new direction of "PURE DRIVE" evolution by operating the internal combustion engine as a power generator.

4) After making the breakthrough for the best BSFC, downsizing will be enhanced in order to reduce thermal energy capacity. Variable compression ratio technology will be an effective solution for this.

\section{Nomenclature}

BEV battery electric vehicle

BSFC brake specific fuel consumption

CVT continuously variable transmission

EGR exhaust gas recirculation
EV electric vehicle

ICE internal combustion engine

SI spark ignition

VC-T variable compression-turbo

\section{Bibliography}

[1] MIYAMOTO, T., WATANABE, Y., HIRAI, T., SASAKI, T. Development of high capacity lithium-ion battery for NISSAN LEAF. SAE Technical Paper. 2012, 2012-01-0664.

[2] MIZUNO, H., ASHIDA, K., TERAJI, A. et al. Transient analysis of the piston temperature with consideration of incylinder phenomena using engine measurement and heat transfer simulation coupled with three-dimensional combustion simulation. SAE Journal Article. 2009, 2009-01-0187.

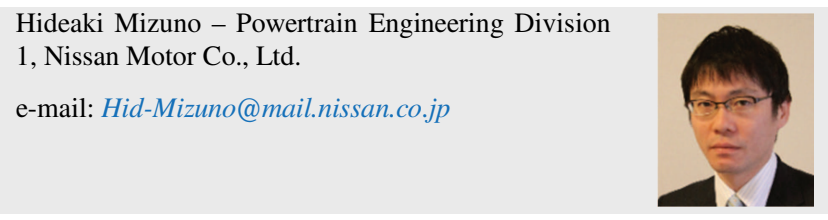

[3] MOTEKI, K., AOYAMA, S., USHIJIMA, K. et al. A study of a variable compression ratio system with a multi-link mechanism. SAE Technical Paper. 2003, 2003-01-0921.

[4] TSUCHIDA, H., HIRAYA, K., TANAKA, D. et al. The effect of a longer stroke on improving fuel economy of a multiple-link VCR engine. SAE Technical Paper. 2007, 2007-01-4004.

[5] HIRAKU, R. Our tasks to make ICE surviving in the coming century. JSAE No.15FORUM-8. 20154338. 